\title{
Letter: Primary Hyperparathyroidism after Roux-en-Y gastric Bypass
}

\author{
Maria de Fátima Haueisen Sander Diniz ${ }^{1}$ - Alline Maria Rezende Beleigoli ${ }^{1}$ • \\ Alexandre Lages Savassi-Rocha ${ }^{1}$ - Soraya Rodrigues de Almeida Sanches ${ }^{1}$. \\ Marco Túlio Costa Diniz ${ }^{1}$
}

Published online: 7 January 2016

(C) Springer Science+Business Media New York 2016

To the Editor:

We read with great interest the article by Chen $\mathrm{Y}$ et al. [1] recently published in Obesity Surgery, which retrospectively investigated all patients with the diagnosis of primary hyperparathyroidism (PHPT) and previous Roux-en-Y gastric bypass (RYGBP). They found ten cases since 2000, and four patients did not have their calcium normalized after the cervical operation.

Like Chen et al. [1], along with 18 years of follow-up of 300 RYGBP patients, we also had two cases of PHPT. Informed consent was obtained from all individual participants included in the study.

Seven and 16 years after RYGBP, two women 50- and 62years-old, respectively, were diagnosed with PHPT. The diagnostic criteria of PHPT were hypercalcemia, high PTH, with normal 25-hydroxy vitamin $\mathrm{D}$, phosphorus and renal function. The patients were submitted to cervical exploration and a single adenoma was detected in both, with postoperative calcium and PTH normalization.

Both made irregular use of the calcium and of the vitamin D in most of the follow-up visits after operation. Besides, similarly to the findings of Chen et al., both presented biochemical deficiency of vitamin D. After bariatric surgery, the attrition rates of vitamin and mineral supplementation are high [2]. We wonder

Maria de Fátima Haueisen Sander Diniz mfhsdiniz@ufmg.br

1 Federal University of Minas Gerais, Belo Horizonte, Minas Gerais, Brazil if the irregular use of vitamin D and calcium supplementation, along with the duodenal exclusion and lower absorption, could generate a persistent stimulation of parathyroid glands, like in chronic renal disfunction [3]. In other words, it is plausible that a longstanding secondary hyperparathyroidism, despite being sometimes "under biochemical control", could-in fact-generate a tertiary hyperparathyroidism.

Despite the important role of bariatric surgery in the control of weight and obesity-related comorbidities in the long term, the multidisciplinary team and patients must be aware of the potential emerging problems during the postoperative follow-up. The interesting paper of Chen et al. reinforces the necessity of a long term follow-up and of mineral and vitamins prescription to patients submitted to RYGBP, in order to prevent longstanding parathyroid stimulation and autonomy.

Thank you,

Maria de Fátima Haueisen Sander Diniz, M.D., Ph.D.

Alline Maria Rezende Beligoli, M.D., Ph.D.

Alexandre Lages Savassi-Rocha, M.D., Ph.D.

Soraya Almeida Rodrigues Sanches, M.D., Ph.D.

Marco Túlio Costa Diniz, M.D., Ph.D.

\section{References}

1. Chen Y, Lubitz CC, Shikora SA, et al. Primary hyperparathyroidism after Roux-en-Y gastric bypass. Obes Surg. 2015;25(4):700-4.

2. Aaseth E, Fagerland MW, Aas AM, et al. Vitamin concentrations 5 years after gastric by-pass. Eur J Clin Nutr. 2015;69(11):1249-55.

3. Souberbielle JC, Bienaimé F, Cavalier E, et al. Vitamin D and primary hyperparathyroidism (PHPT). Ann Endocrinol (Paris). 2012;73(3):165-9. 